Agr. Biol. Chem., 40 (6), $1201 \sim 1208,1976$

\title{
Effect of Lipopolysaccharide from Proteus mirabilis, alone or with Antitumor Agents, against Experimental Animal Tumors ${ }^{\dagger}$
}

\author{
Masaki NaKahara, Mamoru Arai and Hiroshi OKaZAKI \\ Fermentation Research Laboratories, Sankyo Co., Ltd., \\ No. 2-58, Hiromachi 1-chome, Shinagawa-ku, \\ Tokyo 140, Japan \\ Received January 26, 1976
}

\begin{abstract}
Antitumor effect of Lipopolysaccharide (LPS) from Proteus mirabilis RMS-203 was evaluated.

Minimal effective doses detected by the Pigment test of LPS from both wild type and heptoseless mutant against solid-type Ehrlich carcinoma was $0.005 \mathrm{mg} / \mathrm{kg}$ given by either intravenous or intraperitoneal administration. Besides Ehrlich carcinoma, solid-type tumors, such as Sarcomas 180 and 37, Meningeal sarcoma MS-147, Walker carcinosarcoma 256 and Adenocarcinoma 755, were also sensitive to LPS, but several other solid-type tumors, such as Yoshida sarcoma and $\mathrm{C} 3 \mathrm{H}$ spontaneous sarcoma, as well as all ascites form of tumors were insensitive.

Ehrlich carcinoma and Sarcomas 180 and 37 in mice were completely regressed, but other three types of tumors sensitive to LPS by the Pigment test were not cured because of regrowth of the tumors.

The blockage of blood stream into the tumor tissue after administration of LPS to the mice bearing solid-type tumors was clearly demonstrated by exclusion ('Lock out') or by defect in exudation ('Lock in') from the tumor tissues of the injected materials. Using this action of LPS, the mice bearing Meningeal sarcoma MS-147 or Walker carcinosarcoma 256 was successfully treated with combined use of LPS and a small amount of antitumor agent, such as 6mercaptopurine or cyclophosphamide.
\end{abstract}

As previously reported, ${ }^{7}$ the living cells or $P$. mirabilis RMS-203, isolated from the pus of a woman's hepatomegalia, gave oncolytic effect on tumor-bearing mouse without any harmful influence on the host.

Furthermore lipopolysaccharide (LPS) with low toxicity and low pyrogenicity was isolated as an antitumor principle from a heptoseless mutant strain of this organism. ${ }^{8}$

In this paper, antitumor activities of the LPS from $P$. mirabilis, wild type and heptoseless mutant $\mathrm{N}-434$, against several tumors were investigated.

The blockage of blood stream into the tumor tissue after administration of LPS was also examined by quantitative determination of the injected materials inside the tumor tissue.

+ Chemical and Biological Studies on Bacterial Lipopolysaccharide with Antitumor Activity. Part III. See Reference 8) for Part II.
This action of LPS was further applied to the combination therapy of incurable tumors with some other antitumor agents.

\section{MATERIALS AND METHODS}

LPS from P. mirabilis RMS-203. LPS used in the present experiments were isolated from wild type and heptoseless mutant $\mathrm{N}-434$ of $P$. mirabilis RMS-203 by the water-phenol method of Westphal ${ }^{p l}$ and the method of Galanos, ${ }^{3)}$ respectively, as described in the previous reports. ${ }^{1,8)}$

Tumor-bearing animals. When solid tumors were transplanted, small pieces (approximately $2 \mathrm{~mm}$ in diameter) were implanted subcutaneously into the right axilla (or back region in the case of Walker carcinosarcoma 256) of healthy young animals by the usual trocar method.

Pigment test. Vascular effect of LPS on the solidtype tumors was detected by the Pigment test, the modified method of Goldacre and Sylven.. ${ }^{4}$ The 
tumor-bearing animals were injected intravenously with $0.3 \mathrm{ml}$ of $2 \%$ pontamine sky blue $6 \mathrm{~B} 24 \mathrm{hr}$ after administration of LPS and sacrificed $2 \mathrm{hr}$ after injection of the pigment. The tumor tissue of non-treated animal was stained bluish with the pigment whereas that of LPS injected one was not.

Complete regression of tumors. The effectiveness of LPS against various solid-type tumors were evaluated by a complete regression of tumors after 2 to 4 weeks of LPS administration.

Measurement of pontamine sky blue $6 B$ in tissues. Concentration of pontamine sky blue $6 \mathrm{~B}$ in tissues was measured by leading O.D. $200 \mathrm{~m}$ after extraction of the pigment from tissues by the method of Hayashi et al..$^{b}$ For this purpose, the tissues were cut and homogenized in $5 \mathrm{ml}$ of a mixture of $\mathrm{CHCl}_{3}$ and $\mathrm{MeOH}(2: 1)$ by a Universal homogenizer. To the homogenate, $10 \mathrm{ml}$ of $30 \%$ pyridine in water was added, and the pigment was extracted at $80^{\circ} \mathrm{C}$ for $60 \mathrm{~min}$. The extract was filled with distilled water up to $15 \mathrm{ml}$, and O.D. ${ }_{\text {. } 20 \mathrm{~nm}}$ was determined.

Measurement of ${ }^{125}$ I-radioactivity in tissues. Tumor and other tissues were taken out from the mice injected with ${ }^{125}$ I-human serum albumin (produced by Daiichi Pure Chemicals Co., Ltd.) at definite intervals and homogenized by Potter-Ervehjem's glass homogenizer after addition of $5 \sim 8 \mathrm{ml}$ of distilled water. The homogenate was diluted up to $10 \mathrm{ml}$ with distilled water and the radioactivity was counted by Aloka well type $\gamma$-ray spectrometer.

Measurement of total cyclophosphamide in tumor tissues. The amount of total cyclophophamide was measured by the method of Friedman and Boger ${ }^{23}$ modified by Morita et $a l^{8}{ }^{\text {) }}$

\section{RESULTS AND DISCUSSION}

\section{Pigment test}

Table I shows vascular effects of LPS isolated from wild type or heptoseless mutant $\mathrm{N}$ 434 of $P$. mirabilis against Ehrlich solid tumor examined by the Pigment test. Both LPS preparations isolated from the wild type and from the heptoseless mutant $\mathrm{N}-434$ possessed the same level of activity when given by intravenous injection. Concerning the route of injection, quite the same dose response was observed by intraperitoneal injection of the heptoseless LPS as by intravenous injection, but $10^{3}$ times less activity by subcutaneous injection of the same LPS.

The section of the tumor tissues injected with LPS was not colored by the pigment in contrast to that of the control in which tumor tissues were clearly colored in blue as shown in Fig. 1. It is conceivable that failure in the coloration of the tumor tissue in the case of LPS-injected animal might be due to a stagnancy of blood stream, as inferred from the fact that the tumor tissue was gradually injured by asphyxia and undernutrition. Apparently, a necrosis was recognized in the tumor tissue one week after injection of LPS. This phenomenon is therefore called 'Lock out' hereafter.

A complete regression of tumors was noted

Table I. VAscular Effect of LPS Isolated from Proteus mirabilis RMS-203 Examined By the Pigment Test ${ }^{a}$ )

\begin{tabular}{|c|c|c|c|c|c|c|c|}
\hline \multirow{3}{*}{\begin{tabular}{l}
\multicolumn{1}{c}{ Sample } \\
$\begin{array}{l}\text { Control } \\
\text { LPS (from wild type) }\end{array}$
\end{tabular}} & \multirow{2}{*}{$\frac{\begin{array}{c}\text { Dose } \\
\mathrm{mg} / \mathrm{kg}\end{array}}{0}$} & \multirow[t]{2}{*}{$\begin{array}{l}\text { Route of } \\
\text { injection }\end{array}$} & \multicolumn{5}{|c|}{$\begin{array}{c}\text { Result of the Pigment test in } 5 \text { mice in which } \\
\text { pigment was injected } 24 \mathrm{hr} \text { after the administra- } \\
\text { tion of LPS }\end{array}$} \\
\hline & & & $\left.+t^{b}\right)$ & ++ & $+t$ & ++ & $t+$ \\
\hline & 0.0005 & IV & ++ & ++ & + & \pm & \pm \\
\hline & 0.005 & IV & \pm & - & - & - & $=$ \\
\hline & 0.05 & IV & \pm & - & - & - & - \\
\hline & 0.5 & IV & \pm & - & - & - & - \\
\hline & 5 & IV & - & - & - & - & - \\
\hline \multirow{3}{*}{$\begin{array}{l}\text { LPS (from heptoseless } \\
\text { mutant) }\end{array}$} & 0.0005 & IV & ++ & ++ & ++ & \pm & \pm \\
\hline & 0.005 & IV & + & \pm & - & - & - \\
\hline & 0.05 & IV & - & - & - & - & - \\
\hline
\end{tabular}

a) Mice bearing solid-type tumor of Ehrlich carcinoma (7th day after the implantation) were used for the Pigment test.

b) ++ . Tumor tissues were colored $100 \%$ by pontamine sky blue $6 \mathrm{~B}$ (not effective); +.80 to $99 \%$; , \pm 50 to $79 \% ;-, 0$ to $50 \%$ (effective). 

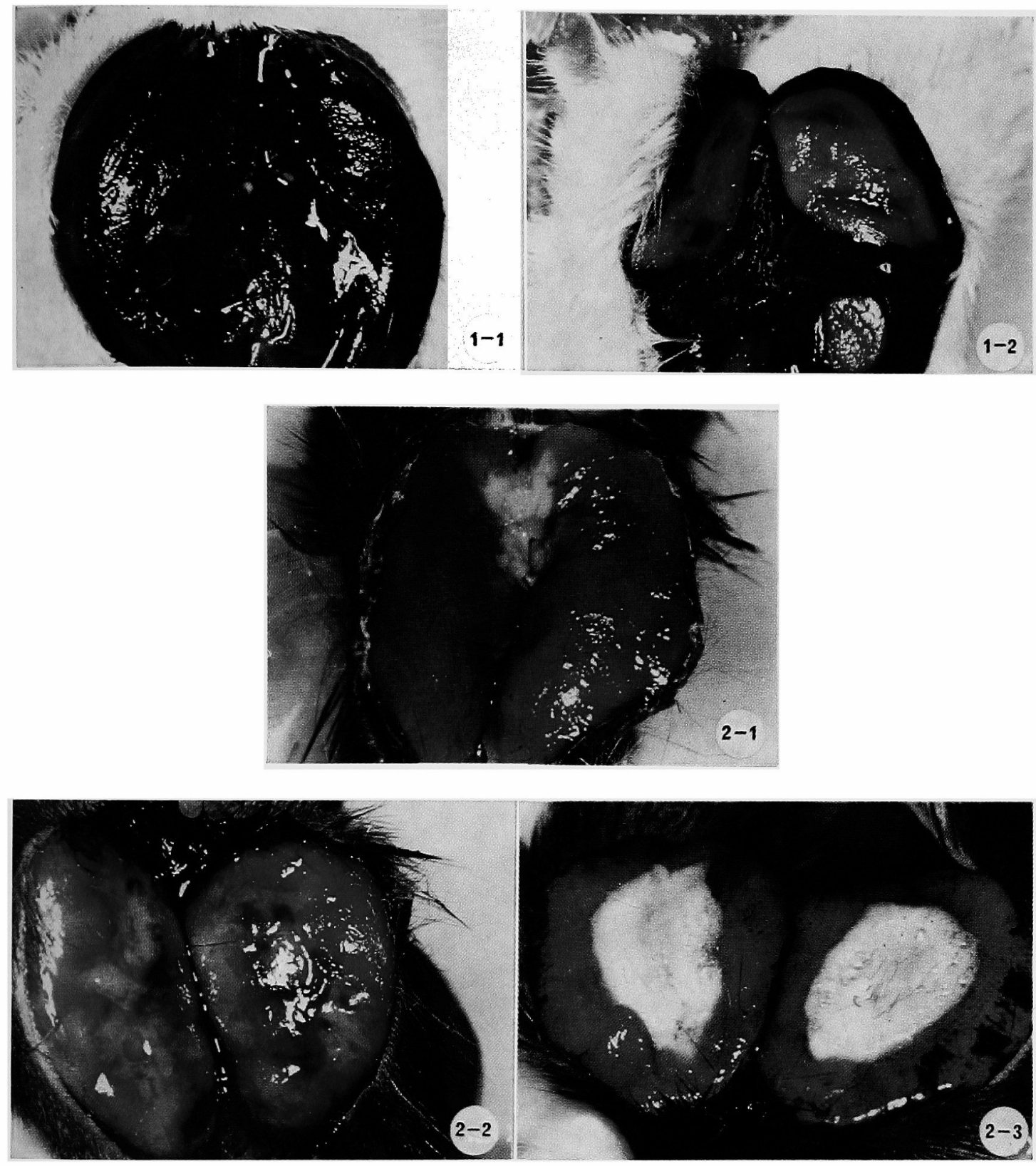

FIG. 1. Effect of LPS against Solid-type Tumors Examined by the Pigment Test.

Mice implanted with tumors at the site of right armpit were injected intravenously with $500 \mu \mathrm{g} /$ $\mathrm{kg}$ of LPS (after 7 days implantation of Ehrlich carcinoma and 8 days of Meningeal sarcoma). $24 \mathrm{hr}$ after administration of LPS, mice were injected with $0.3 \mathrm{ml}$ of $2 \%$ Pontamine sky blue $6 \mathrm{~B}$ via the same route, sacrificed $2 \mathrm{hr}$ later and tumor sections of which are shown in these figures.

1. Ehrlich carcinoma: 1-1 Control, 1-2 LPS treated.

2. Meningeal sarcoma MS-147: 2-1 Control, 2-2 $24 \mathrm{hr}$ after LPS treatment, 2-3 1 week after LPS treatment. 
in other solid-type tumors, such as Sarcoma 180 and Sarcoma 37, but not in Meningeal sarcoma MS-147, Adenocarcinoma 755 and Walker carcinosarcoma 256. LPS from $P$. mirabilis was ineffective against ascites form of tumors, such as Ehrlich carcinoma, Sarcoma 180, Lymphoid leukemia L 1210 and Yoshida sarcoma.

In the case of Meningeal sarcoma MS-147, tumor tissue was scarcely stained by the pigment $24 \mathrm{hr}$ after injection of LPS as shown in Fig. 1. After $72 \mathrm{hr}$, it was stained a little at the peripheries. After one week following the injection of LPS, tumor tissue was stained in a ring form from the peripheries, whereas the central area still remained uncolored. Histological observation of Meningeal sarcoma MS-147 at various intervals following the injection of LPS was in good agreement with the result of the Pigment test. After $24 \mathrm{hr}$ following the injection of LPS, decrease in cell density, heteromorphism or contraction of nucleus and coagulation of chromatin were noticed in the tissue. A complete damage of cells, however, was not achieved in the tumor tissue. After $72 \mathrm{hr}$, pathological figure of the tissue was almost the same as that after $24 \mathrm{hr}$ in most of the tumor tissue region, but regeneration of the tumor was already observed in peripheral region. After 7 days following the injection of LPS, coagulation necrosis was recognized in the central region, but actively growing tumor tissue was recognized in the peripheral region. The zones of regrowth were coincident with those stained by the Pigment test.

\section{A complete regression of tumors}

The results of the antitumor effect on the basis of a complete regression by LPS of solid-type tumor of Ehrlich carcinoma, Sarcoma 180 and Sarcoma 37 are shown in Table II. LPS was markedly effective for inhibition of the growth of these tumors. A complete regression of the tumors was also demonstrated in the mice administered intraperitoneally or subcutaneously with LPS from the heptoseless mutant, although higher doses were required in the latter route of injection.

LPS from wild type or heptoseless mutant of $P$. mirabilis RMS-203 was found to be as active against various types of solid tumor as LPS from other bacteria of Enterobacteriaceae.

As described in the previous report, ${ }^{8)}$ LPS from heptoseless mutant had less toxicity and pyrogenicity as compared with LPS from wild type, but almost the same value of antitumor activity was detected for these two kinds of LPS.

Table II. Effect of LPS on the Solid Type Tumors of Ehrlich Carcinoma, SARCOMA 180, AND SARCOMA 37

\begin{tabular}{|c|c|c|c|c|c|c|}
\hline \multirow{2}{*}{ Sample } & \multirow{2}{*}{$\begin{array}{c}\text { Dose } \\
\mathrm{mg} / \mathrm{kg}\end{array}$} & \multirow{2}{*}{$\begin{array}{l}\text { Route of } \\
\text { injection }\end{array}$} & \multicolumn{4}{|c|}{$\begin{array}{l}\text { No. of mice with completely regressed } \\
\text { tumor after treatment }\end{array}$} \\
\hline & & & 1 week & & 3 weeks & 4 weeks \\
\hline \multicolumn{7}{|l|}{ \$Ehrlich carcinoma } \\
\hline Control & 0 & & $0 / 10^{a)}$ & $0 / 8$ & $0 / 7$ & $1 / 7$ \\
\hline \multirow[t]{3}{*}{ LPS (from wild type) } & 0.005 & IV & $0 / 10$ & $0 / 10$ & $2 / 10$ & $2 / 10$ \\
\hline & 0.05 & IV & $0 / 10$ & $3 / 10$ & $5 / 10$ & $6 / 10$ \\
\hline & 0.5 & IV & $0 / 10$ & $0 / 10$ & $6 / 10$ & $10 / 10$ \\
\hline \multirow[t]{3}{*}{ LPS (from heptoseless mutant) } & 0.005 & IV & $0 / 10$ & $0 / 10$ & $2 / 10$ & $2 / 10$ \\
\hline & 0.05 & IV & $0 / 9$ & $2 / 9$ & $5 / 9$ & $5 / 9$ \\
\hline & 0.5 & IV & $0 / 9$ & $3 / 9$ & $6 / 9$ & $6 / 9$ \\
\hline \multicolumn{7}{|l|}{$\$$ Sarcoma 180} \\
\hline Control & 0 & & $0 / 10$ & $0 / 10$ & $0 / 8$ & $0 / 5$ \\
\hline LPS (from heptoseless mutant) & 1 & IV & $0 / 10$ & $8 / 10$ & $10 / 10$ & $10 / 10$ \\
\hline \multicolumn{7}{|l|}{ \$Sarcoma 37} \\
\hline Control & 0 & & $0 / 10$ & $0 / 9$ & $1 / 6$ & $1 / 2$ \\
\hline LPS (from heptoseless mutant) & 0.5 & IV & $2 / 10$ & $5 / 10$ & $5 / 6$ & $5 / 5$ \\
\hline
\end{tabular}

a) Ten mice in a group were used in each experiment. 
A complete regression of tumors was observed for Ehrlich carcinoma and Sarcomas 180 and 37 but only a temporary inhibition of tumors was detected by the Pigment test for Meningeal sarcoma MS-147, Walker carcinosarcoma 256 and Adenocarcinoma 755. In the cases of latter three types of tumors, vascular effect of LPS against the tumor tissues was apparently observed by the Pigment test, but a complete regression could not be achieved because of regrowth of the tumors.

Ascites form of tumors as well as other types of solid tumors were insensitive to LPS.

Vascular effect of LPS was further investigated to clarify the mechanism of action of LPS against tumors.

'Lock out' of pontamine sky blue and ${ }^{125} \mathrm{I}-\mathrm{hu}$ man albumin from tumor tissue

When LPS was administered to the mice bearing solid-type Ehrlich carcinoma or one of several other kinds of tumors, the tumor tissue was not stained by injection of the pigment to the mice after $24 \mathrm{hr}$. This phenomenon seemed to be accounted for by the fact that blood stream into tumor tissue was so disturbed by administration of LPS that the pigment was excluded from that tissue ('Lock out').

Changes in concentration of pontamine sky

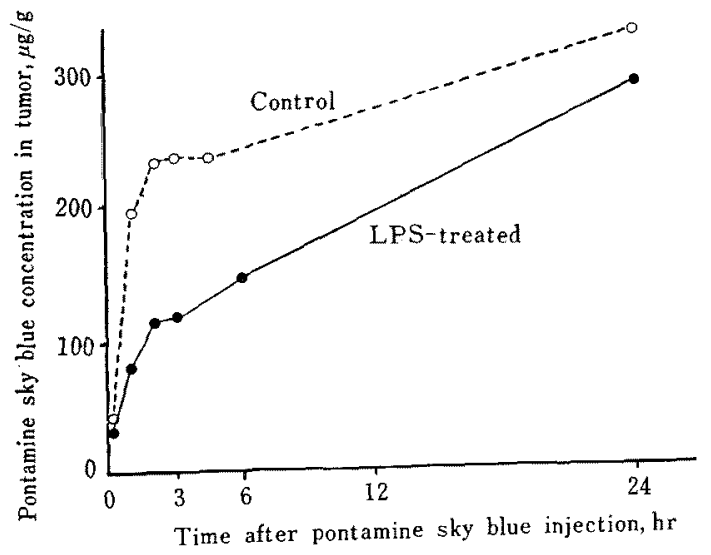

FIG. 2. 'Lock out' of Pontamine Sky Blue from Tumor Tissue in Mouse after LPS Administration.

Pontamine sky blue $6 \mathrm{~B}$ was injected intravenously at a dose of $200 \mathrm{mg} / \mathrm{kg} 24 \mathrm{hr}$ after LPS administration $(1.0 \mathrm{mg} / \mathrm{kg}, \mathrm{IV})$ to the mice bearing solid-type tumor of Ehrlich carcinoma ( 7 th day after the implantation). blue in Ehrlich carcinoma after injection of LPS is shown in Fig. 2. Pontamine sky blue was injected intravenously at a dose of $200 \mathrm{mg} /$ $\mathrm{kg} 24 \mathrm{hr}$ after LPS administration (1.0 mg/ $\mathrm{kg}$, IV). A concentration of pontamine sky blue in the tumor tissue treated with LPS was about a half of that in the non-treated one 3 and $6 \mathrm{hr}$ after injection of the pigment. After $24 \mathrm{hr}$ following pontamine sky blue injection, the difference in pigment concentration was not so conspicuous between the control and the LPS-treated tumor tissue. Therefore, 'Lock out' of the pigment from the tumor tissue by LPS administration was not so strict and the pigment could slowly permeate into the tissue.

Such 'Lock out' phenomenon was also confirmed by the use of ${ }^{125}$ I-human albumin as the marker. ${ }^{125}$ I-Human albumin was injected intravenously at a dose of $5.10 \times 10^{7} \mathrm{cpm} / \mathrm{kg}$ 1,3 and 7 days after LPS administration $(1.0 \mathrm{mg} / \mathrm{kg}, \mathrm{IV})$. As shown in Fig. 3, radioactivity in the control tumor tissue was always higher than that in the LPS-treated one. On the other hand, no difference in concentrations of ${ }^{125}$ I-human albumin in other tissues, such as liver, spleen and kidney, was detected between LPS-treated and non-treated mice. Therefore, this 'Lock out' phenomenon is considered to be specific for the tumor tissue.

Defect in exudation of ${ }^{125}$ I-human albumin from tumor tissue

As mentioned above, 'Lock out' phenomenon was observed specifically in the tumor tissue after LPS administration. Conversely, it could be expected that any material existed in the tumor tissue would be difficult to flow out from that tissue by LPS administration and stay for a long time in it, that is to say 'Lock in' within the tumor tissue. This phenomenon was positively confirmed by using ${ }^{125} \mathrm{I}$-human albumin as a marker.

'Lock in' of ${ }^{125}$ I-human albumin in the tumor tissue by LPS treatment is shown in Fig. 4. The mice bearing Ehrlich carcinoma were injected with ${ }^{125}$ I-human albumin intravenously followed by administration of LPS by the same route 1 hr later. Up to $6 \mathrm{hr}$ after 


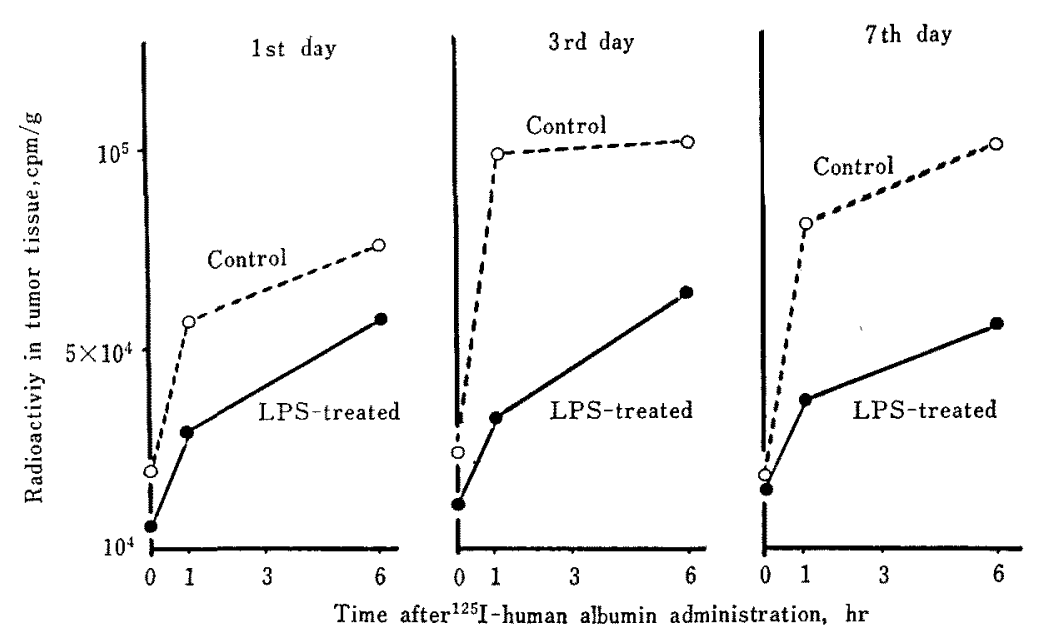

Fig. 3. 'Lock out' of ${ }^{12 s}$ I-Human Albumin from Tumor Tíssue in Mice after Various Days of LPS Administration.

${ }^{125} \mathrm{I}$-human albumin was injected intravenously at a dose of $5.10 \times 10^{7} \mathrm{cpm} / \mathrm{kg} 1,3$ and 7 days after LPS administration $(1.0 \mathrm{mg} / \mathrm{kg}$, IV) to the mice bearing solid-type tumor of Ehrlich carcinoma (7th day after the implantation).

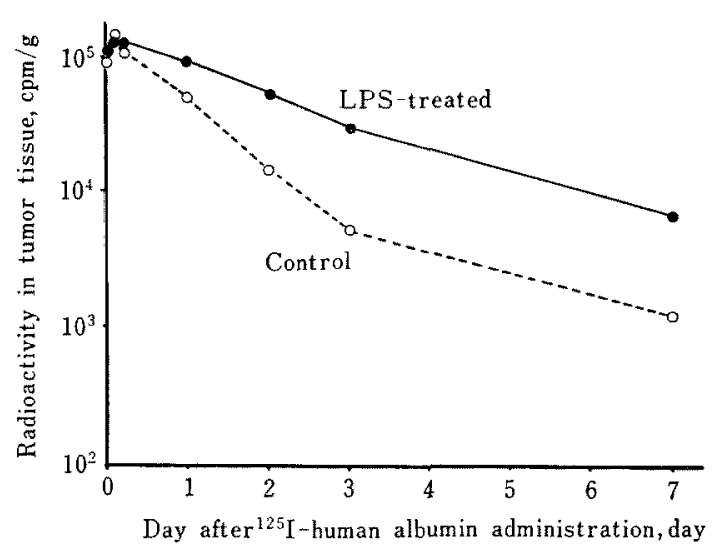

FIG. 4. 'Lock in' of ${ }^{125}$ I-Human Albumin Inside Tumor Tissue of Mice after LPS Administration.

${ }^{125}$ I-Human albumin was injected intravenously at a dose of $5.10 \times 10^{7} \mathrm{cpm} / \mathrm{kg} 1 \mathrm{hr}$ after LPS administration $(1.0 \mathrm{mg} / \mathrm{kg}, \mathrm{IV})$ to the mice bearing solid-type tumor of Ehriich carcinoma ( 7 th day after the implantation).

the injection of radioactive albumin, no difference in radioactivity retained was found between the control and LPS-treated tumor tissue. With the lapse of time, however, difference became more and more apparent, and about 5 times higher radioactivity was found in the LPS-treated tumors than in the control from 3 to 7 days.

\section{Combination therapy with LPS and antitumor agents}

As in the case of tumors such as Meningeal sarcoma MS-147 and Walker carcinosarcoma 256 , complete regression was not recognized even by long-term observation after the injection of LPS alone in spite of the vascular damage observed by the Pigment test. Therefore, in this experiment, a trial of combination therapy with LPS and antitumor substances was done under the idea that LPS will lock in the antitumor substances inside the tumor tissue for a long time, which will give rise to complete regression of the tumors.

$\mathrm{BDF}_{1}$ mice implanted with Meningeal sarcoma MS-147 8 to 10 days after the implantation were injected intraperitoneally with 6mercaptopurine at a dose of $50 \mathrm{mg} / \mathrm{kg} /$ day for 5 consecutive days, and were injected intravenously with LPS at a dose of $500 \mu \mathrm{g} / \mathrm{kg}$ of body weight at the same time with the last 6mercaptopurine administration. The results are summarized in Table III. The inhibition percent of tumor growth by 6-mercaptopurine administration alone was $52.1 \%$, that by LPS administration alone was $3.3 \%$, while the inhibition of tumor growth by the combination therapy was $89.3 \% 4$ weeks after the trea- 
Table III. Antitumor Effect of Combined Action of LPS And 6-Mercaptopurine (6-MP) AGainst MENINGeAl Sarcoma MS-147

Mice bearing Meningeal sarcoma MS-147 were injected intraperitoneally with 6-MP at a dose of $50 \mathrm{mg} /$ $\mathrm{kg} /$ day for 5 days starting on the $8 \sim 10$ th day after the implantation and then were injected intravenously with LPS at a dose of $500 \mu \mathrm{g} / \mathrm{kg}$ at the same time of the last 6-MP administration.

\begin{tabular}{|c|c|c|c|c|c|c|c|}
\hline & & \multirow{2}{*}{$\begin{array}{c}\text { Time of } \\
\text { injection } \\
\text { (day) }\end{array}$} & \multirow[b]{2}{*}{$1 \mathrm{~W}$} & \multicolumn{2}{|c|}{ Inhibition rate } & \multirow[b]{2}{*}{$4 W$} & \multirow{2}{*}{$\begin{array}{l}\text { Complete } \\
\text { regression } \\
\quad(4 \mathrm{~W})\end{array}$} \\
\hline & & & & $2 W$ & $3 W$ & & \\
\hline Control, saline & IP $\times 5$ & $8 \sim 10$ & $0 \%$ & $0 \%$ & $0 \%$ & $0 \%$ & $0 / 30$ \\
\hline 6-MP $50 \mathrm{mg} / \mathrm{kg}$ & $\mathrm{IP} \times 5$ & 9 & 4.3 & 36.0 & 58.1 & 52.1 & $0 / 10$ \\
\hline LPS $500 \mu \mathrm{g} / \mathrm{kg}$ & IV & 10 & 22.5 & -2.6 & -3.1 & 3.3 & $0 / 10$ \\
\hline $\begin{array}{c}6-\mathrm{MP} 50 \mathrm{mg} / \mathrm{kg} \\
+\end{array}$ & $\mathrm{IP} \times 5$ & $8 \sim 9$ & 29.9 & 76.3 & 90.5 & 89.3 & $6 / 19$ \\
\hline \multicolumn{8}{|c|}{ LPS $500 \mu \mathrm{g} / \mathrm{kg}$ IV } \\
\hline
\end{tabular}

tment. Only in the case of combination therapy, a complete regression was recognized in 6 out of 19 treated animals.

Wistar-Imamichi rats implanted with Walker carcinosarcoma 2567 days before were injected intraperitoneally with 6-mercaptopurine at a dose of $30 \mathrm{mg} / \mathrm{kg}$ once a day for 5 days and were injected intravenously with LPS at a dose of $25 \mu \mathrm{g} / \mathrm{kg}$ at the time of the last 6mercaptopurine administration. The results are shown in Fig. 5. The inhibition of tumor growth with 6-mercaptopurine alone, LPS alone and the combined therapy with both of

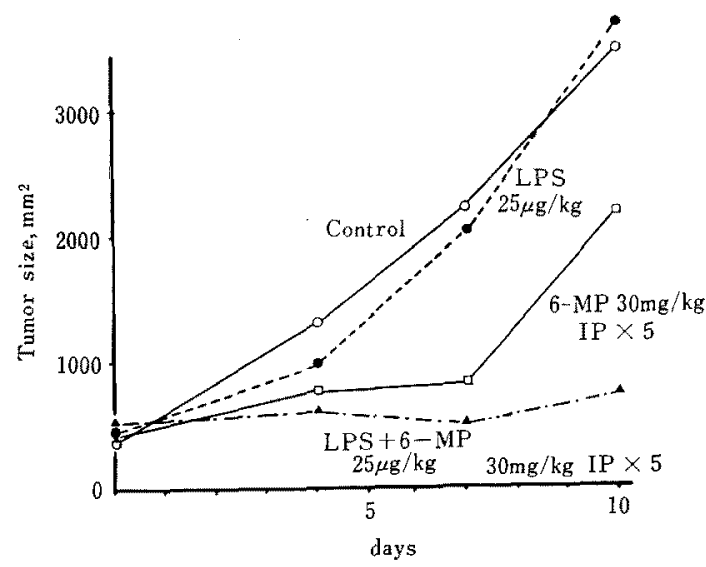

FIG. 5. Antitumor Effect of Combined Action of LPS and 6-Mercaptopurine against Walker Carcinosarcoma 256.

Rats bearing Walker carcinosarcoma ( 7 th day after the implantation) were injected intraperitoneally with 6-mercaptopurine (6-MP) at a dose of $30 \mathrm{mg} / \mathrm{kg}$ once a day for 5 days and were injected intravenously with LPS at a dose of $25 \mu \mathrm{g} / \mathrm{kg}$ at the time of the last 6-MP administration. them were $37.6 \%,-5.5 \%$ and $78.1 \%$, respectively, after 10 days of initiation of the treatment.

It is known that immune factors play a role in the complete regression induced by either 6mercaptopurine or LPS in certain mouse tumors. However, highly effective result indicated by combination therapy of Walker adenocarcinosarcoma 256 with LPS and 6mercaptopurine might be ascribed to vascular effect of LPS. In the presence of LPS, 6mercaptopurine would remain inside the tumor tissue caused by the same 'Lock in' phenomenon as observed with pontamine sky blue or ${ }^{125} \mathrm{I}$-human albumin and also with cyclophosphamide as will be described hereafter.

Another experiment was carried out using LPS and cyclophosphamide against Walker carcinosarcoma 256 after 7 days following implantation to Wistar-Imamichi rats. Rats were injected intravenously with LPS at a dose of $3.1 \sim 6.3 \mu \mathrm{g} / \mathrm{kg}$ and simultaneously with cyclophosphamide at a dose of $1.25 \mathrm{mg} / \mathrm{kg}$. The inhibitions of tumor growth in percent with cyclophosphamide, LPS and the combined therapy with both agents were $41.9 \%, 30.2 \%$ and $86.7 \sim 87.1 \%$, respectively, 10 days after initiation of the treatment. In combination of LPS with cyclophosphamide, the degree of inhibition was not influenced by the dose level of LPS at 3.12 or $6.3 \mu \mathrm{g} / \mathrm{kg}$ as shown in Fig. 6 . In the combination therapy, a complete regression of tumor was observed in 9 out of 20 treated rats. Changes in cyclophosphamide 


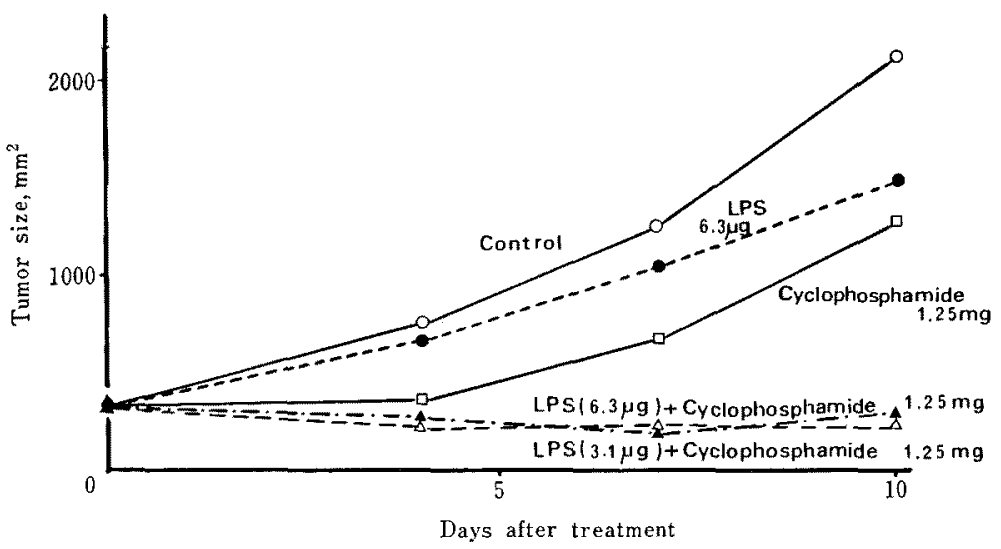

FIG. 6. Antitumor Effect of Combined Action of LPS and Cyclophosphamide against Walker Carcinosarcoma 256.

Rats bearing Walker carcinosarcoma 256 ( 7 th day after the implantation) were injected intravenously with LPS at a dose of $3.1 \sim 6.3 \mu \mathrm{g} / \mathrm{kg}$ and with cyclophosphamide at a dose of $1.25 \mathrm{mg} / \mathrm{kg}$ at the same time.

$\mathrm{O}-\mathrm{O}$, control; --- LPS $6.3 \mu \mathrm{g} ; \square-\square$, cyclophosphamide $1.25 \mathrm{mg} ; \boldsymbol{\Delta}--\mathbf{\Delta}$, LPS $(6.3 \mu \mathrm{g})$ +cyclophosphamide $1.25 \mathrm{mg} ; \triangle--\triangle$, LPS $(3.1 \mu \mathrm{g})+$ cyclophosphamide $1.25 \mathrm{mg}$.

content in the tumor tissue after injection of cyclophosphamide alone or both LPS and cyclophosphamide $(100 \mathrm{mg} / \mathrm{kg})$ are shown in Fig. 7. Evidently, the content of cyclophosphamide in the tumor tissue was higher with combined treatment than with cyclophosphamide alone. Thus, the combined therapies were proved to be effective for keeping a high level of antitumor agent in the tumor tissue.

Finally, it might be suggested that a complete regression of various types of tumor should be achieved by two approaches. The first is to

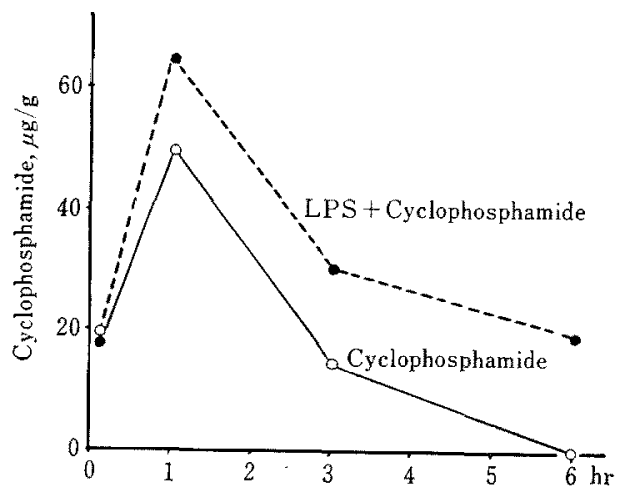

FIG. 7. Cyclophosphamide Content in Walker Carcinosarcoma 256 Tumor Tissue after Treatment.

Rats bearing Walkar carcinosarcoma 256 (7th day after the implantation) were injected intravenously with LPS at a dose of $3.1 \mu \mathrm{g} / \mathrm{kg}$ and cyclophosphamide at a dose of $100 \mathrm{mg} / \mathrm{kg}$ at the same time. obtain less toxic and more specifically active component of LPS by the use of the advanced techniques in the fields of biochemistry and microbiology in the future. The second is to combine LPS with other antitumor agents as described in this paper.

Acknowledgements. We are grateful to Dr. Takashi Okonogi for his invaluable help in histological observation and to Dr. Masao Arakawa for his supply of various experimental tumors. We are also indebted to them for useful discussions throughout this work.

\section{REFERENCES}

1) M. Arai, M. Nakahara, K. Hamano and H. Okazaki, Agr. Biol. Chem., 39, 1813 (1975).

2) O. M. Friedman and E. Boger, Analy. Chem., 33, $906(1961)$.

3) C. Galanos, O. Lüderitz and O. Westphal, Eur.J. Biochem., 9, 245 (1969).

4) R. J. Goldacre and B. Sylven, Brit. J. Cancer, 16, 306 (1962).

5) H. Hayashi, M. Yoshinaga, M. Kono, H. Miyoshi and M. Matsumura, Brit. J. Exp. Pathol., 45, 419 (1964).

6) M. Morita, Y. Tochino, T. Iwata and T. Mineshita Shionogi Kenkyusho Nenpo, 17, 114 (1967).

7) T. Murata, M. Arakawa, Y. Sugiya, Y. Inazu, Z. Hattori, Y. Suzuki, H. Minakami, M. Nakahara and H. Okazaki, Life Sci., 4, 1055 (1965).

8) M. Nakahara, N. Kitahara, K. Hamano, M. Arai and H. Okazaki, Agr. Biol. Chem., 39, 1821 (1975).

9) O. Westphal, O. Lüderitz and F. Biester, $Z$. Naturforsch., 7b, 148 (1952). 